\title{
A STUDY ON WAVE-INDUCED PARTICLE VELOCITIES IN FLUID MUD LAYER
}

\author{
Mohsen Soltanpour ${ }^{1}$, Hadi Shamsnia ${ }^{1}$, Tomaya Shibayama ${ }^{2}$, Ryota Nakamura² ${ }^{2}$ and Akifumi \\ Tatekoji $^{2}$
}

\begin{abstract}
Cohesive sediments can be found in many coastal zones all over the world. The upper layer of these muddy coasts may be fluidized under the wave action. Fluid mud is also formed by settlement of fine particles when the waves and currents exert a small shearing stress on the bed. When the waves pass over the fluid mud layer, it absorbs wave energy and, in turn, moves due to the wave action. The present study offers a numerical and experimental study of wave-mud interaction on a horizontal bed. A number of wave flume laboratory tests are presented to investigate wave attenuation, particle velocities in fluid mud layer and mud mass transport under different wave characteristics. The laboratory results are also compared with a developed semi-analytical model.
\end{abstract}

Keywords: wave-mud interaction; wave attenuation; mud particle velocities; mud mass transport

\section{INTRODUCTION}

In muddy areas, the overlaying wave generates an intermediate wave in the soft fluid mud layer, which oscillates the mud particles resulting to a steady Lagrangian current within fluid mud layer, called mud mass transport. Although this current is small in magnitude, it has a major contribution to the total sediment transport because of the high density of fluid mud layer. Mud mass transport may be partially responsible for huge sedimentation in access channels of the ports in muddy areas after the storms.

Since Gade (1958), who first studied the effects of bottom mud layers on the wave attenuation, several studies have been carried on wave-mud interaction. Dalrymple and Liu (1978) developed a twolayered fluid model to examine the attenuation of waves over a muddy bed, which was characterized as a laminar viscous fluid. They proposed an analytical model for definite mud depths and an analytical boundary layer approximation for the case of a thin mud layer. Mass transport in a two-layered fluid system was first simulated by Dore (1970). Sakakiyama and Bijker (1989) conducted experiments on wave damping and mud mass transport. The mud motion was investigated by using colored mud, with the same water content as the experimental mud, as a tracer. The colored mud in the small box was inserted into the mud layer at a right angle to the flume wall by a piston cylinder system. Then the box was removed leaving a sheet of colored mud in the mud layer without disturbance. A transparent plastic box was later used for taking the sample out. Shibayama et al. (1990) also used colored mud to measure the mass transport for different high and low mud densities, showing the maximum mud transport for the water content ratio of \%214. The approximate measurement of mass transport by dyed mud as a tracer was also followed by a few other researchers (e.g., An and Shibayama, 1994; Soltanpour et al., 2007). However, taking sample of the profile of transported colored mud is not always successful. The profile may considerably change by running similar test conditions too. Another difficulty is choosing the proper duration of wave action, which cannot be adopted very short since the effects of inertial force and thixotropy will become large. For the longer duration times, on the other hand, the circulation of the mud may occur.

Hsu et al. (2013) studied wave-induced mud transport using Electromagnetic Current Meter (ECM, ACM2-RS) for measuring the particle velocities inside the fluid mud. Applying synchronization technique, one ECM was employed for measuring horizontal and vertical velocities at the preselected locations. The wave attenuation over the kaolinite bed and particle velocities in the mud layer were investigated by both laboratory experiments and numerical modeling.

The present study aims to investigate wave attenuation rate, mud particle velocities and mass transport through series of wave flume laboratory experiments and numerical modeling. ECM sensors are employed to capture the mud particle velocities in the fluid mud layer.

${ }^{1}$ Civil Engineering Department, K. N. Toosi university of technology, No.1346, Vali-Asr St., Tehran, P.C. 1996715433, Iran

2 Civil and Environmental Department, Waseda University, Coastal Engineering Laboratory3-4-1 Okubo, Shinjukuku, Tokyo, 169-8555, Japan 


\section{LABORATORY EXPERIMENTS}

\section{Experimental Setup}

The experiments were conducted in the wave flume of the Coastal Engineering Laboratory of the Department of Civil and Environmental Engineering at Waseda University, Japan (Fig. 1). It is equipped with a piston-type wave maker and two glass sidewalls. False beds were constructed at the wave flume, creating a trench to hold the fluid mud. A mixture of kaolinite and tap water was used as the fluid mud layer with the thickness of $0.11 \mathrm{~m}$. The flume was then slowly filled with tap water, up to the total depth of $0.4 \mathrm{~m}$, in order to avoid disturbing the mud layer. Before and after the test runs, fluid mud at some locations were sampled to define the water content ratio.

Measuring the time-dependent velocity profiles in highly turbid water, with a concentration of $\mathrm{O}$ (100) g/L, requires special devices as optical instruments are probably not applicable (Hsu et al., 2013). The accurate measuring device of Electromagnetic Current Meter (ECM), which has been proved to be applicable in both the clear water and highly concentrated fluid mud (400 kg/m3), was chosen for this research. Small diameter of the selected ECMs (VM-801H), in the orders of 4 milliliters, facilitates the concurrent measurements of the velocity time series.

In order to make sure about the reliable performance of the new ECM devices in the dense mud layer, some pretests were performed by manual moving of the sensors. Comparing the measured velocities of ECMs and PIV showed acceptable agreements.

The ECMs were fixed at preselected locations (i.e. $\mathrm{z}=0.02,0.05,0.085,0.12$, and $0.15 \mathrm{~m}$ above the bed), where the first three sensors were used to capture the particle velocities in the fluid mud layer, and the latter two were installed in the water layer to measure the particle velocities near water-mud interface and above that level (Fig. 2). In order to capture the wave attenuation on the muddy bed, four wave gauges were also applied along the wave flume (Fig. 1). Five ECMs and one of the wave gauges were installed exactly in a vertical line in order to visualize the response of two-layered water-mud fluid system (e.g. see Fig. 2d).

Commercial kaolinite was used as the fluid mud bed because of its similar rheological behavior with natural mud and also due to its reproducible properties and easy handling. All the test runs were started by mixing water with the commercial kaolinite. The mixing and continuous stirring were carried out with care so that a uniform mud concentration could be achieved throughout the flume although some small disturbances were inevitable. The viscosity of mixed kaolinite and water was adopted from laboratory tests of Soltanpour and Samsami (2011), conducted on the same kaolinite. Different wave characteristics were applied and time series of particle velocities in both water and fluid mud layers were measured. Table 1 presents the conditions of laboratory tests.

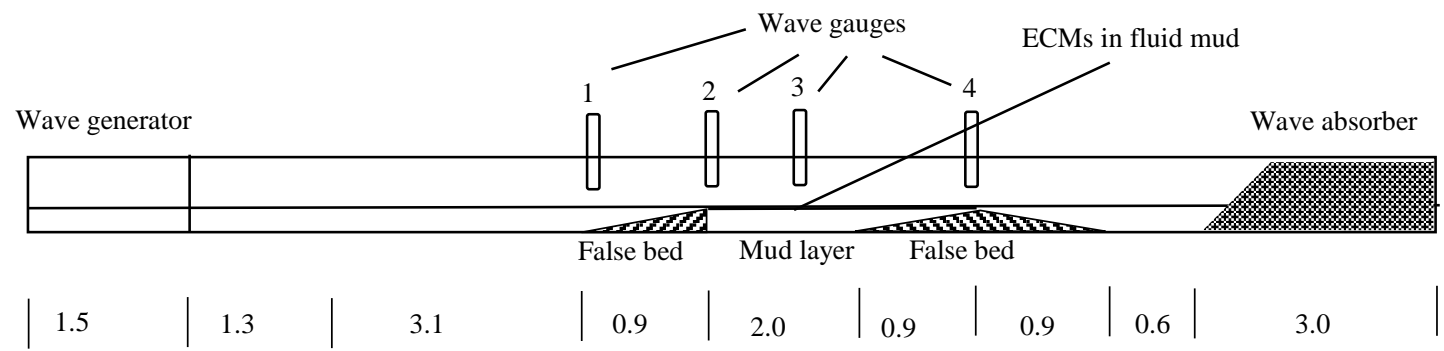

Figure 1. Sketch of the wave flume experimental setup (dimensions in $\mathrm{m}$ ). 


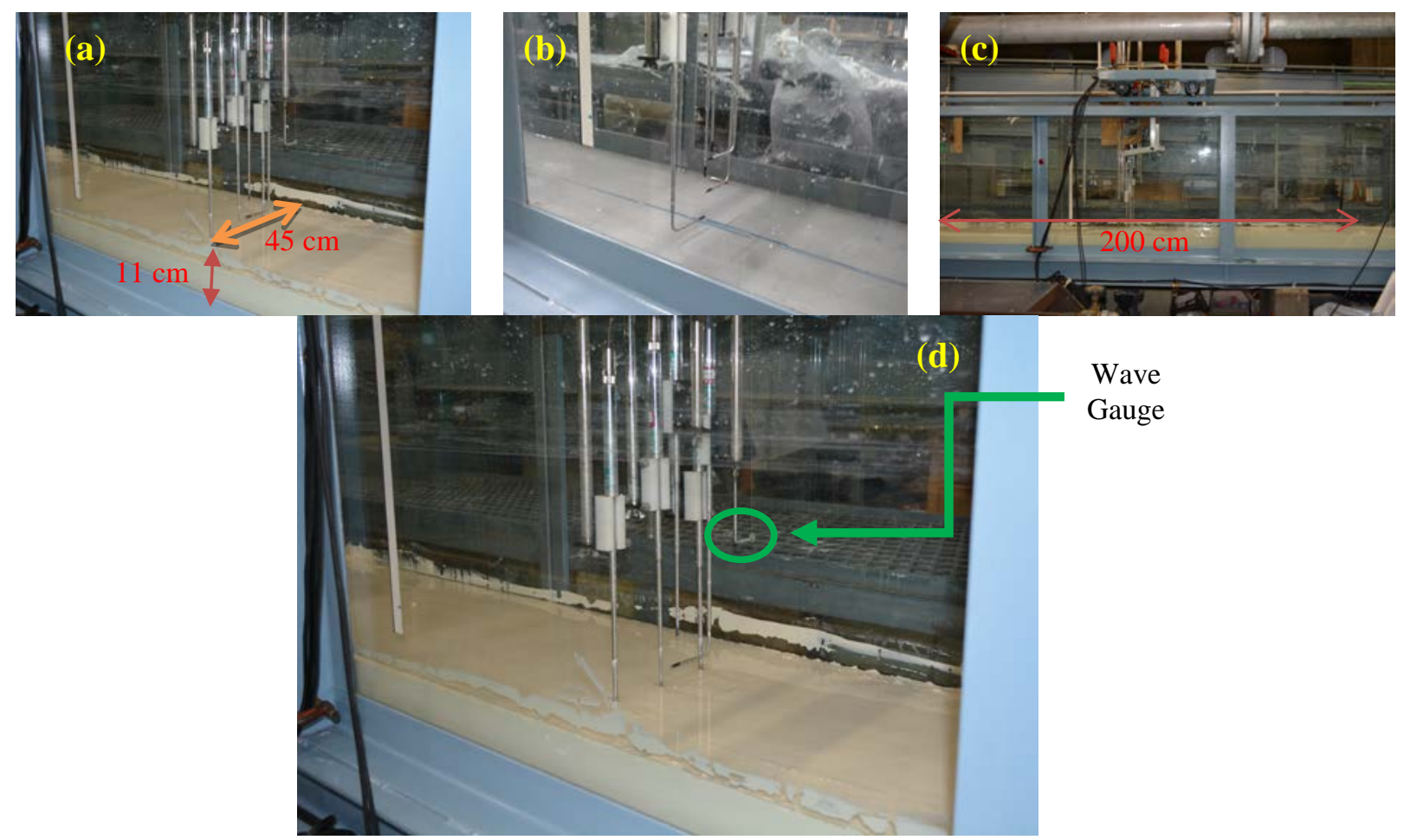

Figure 2. (a) A side view of the measuring devices and mud layer (b) A view of the setup of ECMs at the wave flume (c) Mud section (d) wave gauge over the ECMs.

\section{THEORETICAL CONSIDERATIONS}

\section{Governing Equations}

The fluid system is divided into two sub-layers, in which the water and mud layers are represented by $N=1$ and $N=2$, respectively (Fig. 3). The governing linearized Navier-Stokes equations, neglecting the fluctuating terms and convective accelerations in the water and mud layers are expressed by (Dalrymple and Liu, 1978)

$$
\begin{gathered}
\frac{\partial \hat{u}_{j}}{\partial t}=-\frac{1}{\rho_{j}} \frac{\partial \hat{p}_{j}}{\partial x}+v_{j}\left(\frac{\partial^{2} \hat{u}_{j}}{\partial x^{2}}+\frac{\partial^{2} \hat{u}_{j}}{\partial z^{2}}\right) \\
\frac{\partial \hat{w}_{j}}{\partial t}=-\frac{1}{\rho_{j}} \frac{\partial \hat{p}_{j}}{\partial z}+v_{j}\left(\frac{\partial^{2} \hat{w}_{j}}{\partial x^{2}}+\frac{\partial^{2} w_{j}}{\partial z^{2}}\right) \\
\frac{\partial \hat{u}_{j}}{\partial x}+\frac{\partial \hat{w}_{j}}{\partial z}=0
\end{gathered}
$$

where the subscripts $j=1,2$ respectively represent the water and mud layers, $x$ and $z$ are the horizontal and vertical coordinates, $\hat{u}$ and $\hat{w}$ are the horizontal and vertical components of orbital velocity, and $t, \rho, v$ and $\hat{p}$ represent the time, density, Kinematic viscosity and dynamic pressure, respectively. 


\begin{tabular}{|c|c|c|c|c|}
\hline No. & $T(\mathrm{~s})$ & $H(\mathrm{~cm})$ & $h(\mathbf{c m})$ & $d(\mathrm{~cm})$ \\
\hline 1 & 0.7 & 5.0 & 30 & 11 \\
\hline 2 & 0.7 & 8.0 & 30 & 11 \\
\hline 3 & 0.8 & 4.0 & 30 & 11 \\
\hline 4 & 0.8 & 5.0 & 30 & 11 \\
\hline 5 & 0.8 & 8.0 & 30 & 11 \\
\hline 6 & 0.8 & 7.0 & 30 & 11 \\
\hline 7 & 0.9 & 4.0 & 30 & 11 \\
\hline 8 & 0.9 & 5.0 & 30 & 11 \\
\hline 9 & 0.9 & 8.0 & 30 & 11 \\
\hline 10 & 1.0 & 4.0 & 30 & 11 \\
\hline 11 & 1.0 & 5.0 & 30 & 11 \\
\hline 12 & 1.0 & 7.0 & 30 & 11 \\
\hline 13 & 1.0 & 8.0 & 30 & 11 \\
\hline 14 & 1.1 & 5.0 & 30 & 11 \\
\hline 15 & 1.1 & 7.0 & 30 & 11 \\
\hline 16 & 1.1 & 8.0 & 30 & 11 \\
\hline 17 & 1.2 & 4.0 & 30 & 11 \\
\hline 18 & 1.2 & 5.0 & 30 & 11 \\
\hline 19 & 1.2 & 7.0 & 30 & 11 \\
\hline 20 & 1.2 & 8.0 & 30 & 11 \\
\hline 21 & 1.3 & 5.0 & 30 & 11 \\
\hline 22 & 1.3 & 8.0 & 30 & 11 \\
\hline 23 & 1.5 & 4.0 & 30 & 11 \\
\hline 24 & 1.5 & 7.0 & 30 & 11 \\
\hline 25 & 1.7 & 7.0 & 30 & 11 \\
\hline 26 & 2.0 & 4.0 & 30 & 11 \\
\hline
\end{tabular}

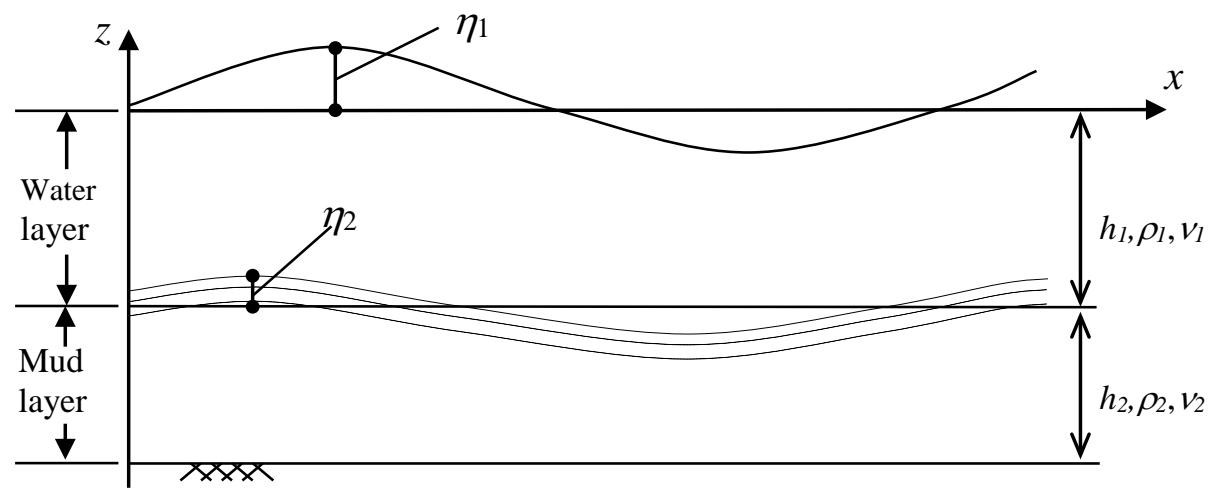

Figure 3 Definition sketch of two-layered wave-mud interaction model. 
The separable, periodic solutions for $\hat{u}_{j}, \hat{w}_{j}, \hat{p}_{j}$ can be assumed as

$$
\left\{\begin{array}{l}
\hat{u}_{j}(x, z ; t)=u_{j}(z) \exp [i(k x-\omega t)] \\
\hat{w}_{j}(x, z ; t)=w_{j}(z) \exp [i(k x-\omega t)] \\
\hat{p}_{j}(x, z ; t)=p_{j}(z) \exp [i(k x-\omega t)]
\end{array}\right.
$$

where $\omega$ is the angular frequency of wave and $k$ is the unknown complex wave number, namely

$$
k=k_{r}+i k_{i}
$$

Displacements of the surface of water and mud layers, $\eta_{j}$, are represented by the following equation

$$
\eta_{j}=a_{j} \exp [i(k x-\omega t)]
$$

where $a_{j}$ represents the amplitude of the water displacement $(j=1)$, and the amplitude of intermediate wave on mud layer $(j=2)$.

Substituting the real and imaginary parts of wave number into Eq. (8), the expression of water surface can be obtained as

$$
\eta_{1}=a_{1} \exp \left(-k_{i} x\right) \exp \left[i\left(k_{r} x-\omega t\right)\right]
$$

Hence, the real part of the wave number, $k_{r}$, gives the wave length $L=2 \pi / k_{r}$ and its imaginary part, $k_{i}$, presents the wave damping coefficient, assuming the exponential wave height decay.

\section{Boundary Conditions}

The boundary conditions include kinematic boundary conditions, which are the continuity of horizontal and vertical velocities at mud-water interface and zero horizontal and vertical velocities at the rigid bottom. The imposition of zero normal stress at the water surface and the continuity of normal and tangential stresses across the interface are the other necessary conditions, i.e. the dynamic boundary conditions. Herein, 9 boundary conditions are required for a two-layered system of water fluid-mud. The boundary conditions are

- At the water surface $\left(z=\eta_{1}\right)$

The kinematic boundary condition, requiring the surface particles to follow the surface, and the imposition of zero normal stress can be written as

$$
\begin{gathered}
\frac{\partial \eta_{1}}{\partial t}=\hat{w}_{1} \\
\hat{p}_{1}-2 \rho_{1} v_{1} \frac{\partial \hat{w}_{1}}{\partial z}=0
\end{gathered}
$$

- At the water-mud interface $\left(z=-h_{1}+\eta_{2}\right)$

The kinematic and dynamic conditions are

$$
\begin{gathered}
\frac{\partial \eta_{2}}{\partial t}=\hat{w}_{2} \\
\hat{u}_{1}=\hat{u}_{2} \\
\hat{w}_{1}=\hat{w}_{2} \\
\hat{p}_{1}-2 \rho_{1} v_{1} \frac{\partial \hat{w}_{1}}{\partial z}=\hat{p}_{2}-2 \rho_{2} v_{2} \frac{\partial \hat{w}_{2}}{\partial z} \\
\rho_{1} v_{1}\left(\frac{\partial \hat{u}_{1}}{\partial z}+\frac{\partial \hat{w}_{1}}{\partial x}\right)=\rho_{2} v_{2}\left(\frac{\partial \hat{u}_{2}}{\partial z}+\frac{\partial \hat{w}_{2}}{\partial x}\right)
\end{gathered}
$$

- At the rigid bottom $\left(z=-h_{1}-h_{2}\right)$

$$
\hat{u}_{2}=0
$$




$$
\hat{w}_{2}=0
$$

where $h_{1}$ and $h_{2}$ are the water and mud depths, respectively.

\section{First Order Solutions}

Introducing of Eqs. (4) and (5) into the continuity Eq. (3) results to

$$
u_{j}=\frac{i w_{j}{ }^{\prime}}{k}
$$

Substituting of Eq. (19) into Eq. (1) yields an expression for $p_{j}$

$$
p_{j}=\frac{\rho_{j} v_{j}}{k^{2}}\left(w_{j}{ }^{\prime \prime}-w_{j}{ }^{\prime} \lambda_{j}^{2}\right)
$$

where

$$
\lambda_{j}^{2}=k^{2}-i \omega v_{j}^{-1}
$$

Introduction of $p_{\mathrm{j}}$ into the vertical momentum, Eq. (2), yields the forth order differential equation for $w_{j}$

$$
w_{j}{ }^{\prime \prime \prime}-\left(k^{2}+\lambda_{j}^{2}\right) w_{j}{ }^{\prime}+k^{2} \lambda_{j}^{2} w_{j}=0
$$

The solutions can be obtained as

$$
\begin{gathered}
w_{j}(z)=A_{j} \sinh k\left(\sum_{n=1}^{j} h_{n}+z\right)+B_{j} \cosh k\left(\sum_{n=1}^{j} h_{n}+z\right)+ \\
C_{j} \exp \left[\lambda_{j}\left(\sum_{n=1}^{j-1} h_{n}+z\right)\right]+D_{j} \exp \left[-\lambda_{j}\left(\sum_{n=1}^{j} h_{n}+z\right)\right]
\end{gathered}
$$

The complex constants $A_{j}, B_{j}, C_{j}, D_{j}$, and the unknown variables $k$ and $a_{2}$ are determined from boundary conditions.

\section{RESULTS AND DISCUSSION}

Fig. 4 shows the changes of the wave attenuation rate versus wave period for the given wave heights. The measured damping rates show two peaks with respect to the wave periods. Same trends of double-pick dissipation rates were observed through the laboratory results of Hsu et al. (2013). However, the viscous model of Dalrymple and Liu (1978) predicts one local peak for the wave dissipation rate, in respect to the wave period, when the boundary layer thickness is of the same order as the mud layer. The trend of one-pick dissipation rate can also be seen in the laboratory tests of Sakakiyama and Bijker (1989) for fluid mud densities smaller than $1310 \mathrm{~kg} / \mathrm{m}^{3}$.

A series of comparisons were conducted to demonstrate the ability of the numerical model to predict different phenomena of wave-mud interaction. Fig. 5 summarizes the agreements between the simulated and measured wave heights on the mud layer for different test runs. Fig. 6 presents the comparisons between the measured amplitudes of particle velocities at different mud depths with the simulated values. It is observed that the proposed model is capable of predicting the velocity amplitudes. Fig. 7 offers sample comparisons of the time series of the simulated and measured particle velocities at three different locations in the mud layer as well as overlaying water layer. 

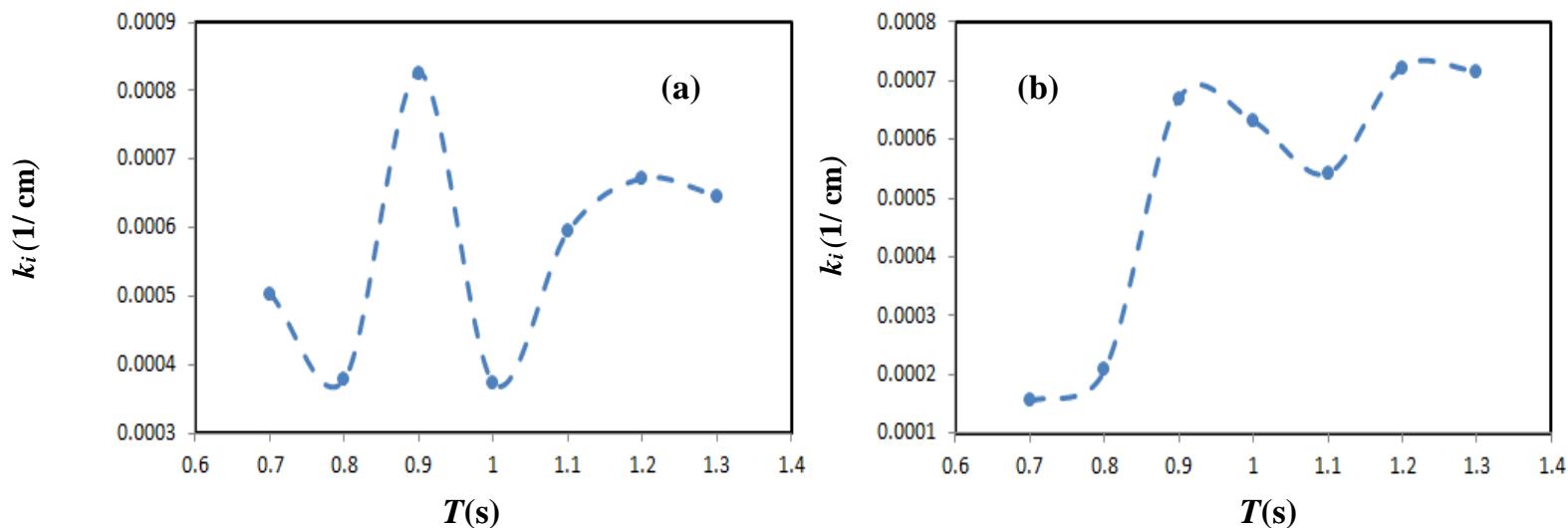

Figure 4. Relationship between wave attenuation rate and wave period for different wave heights; (a) $H=5$ cm; (b) $H=8 \mathrm{~cm}$.

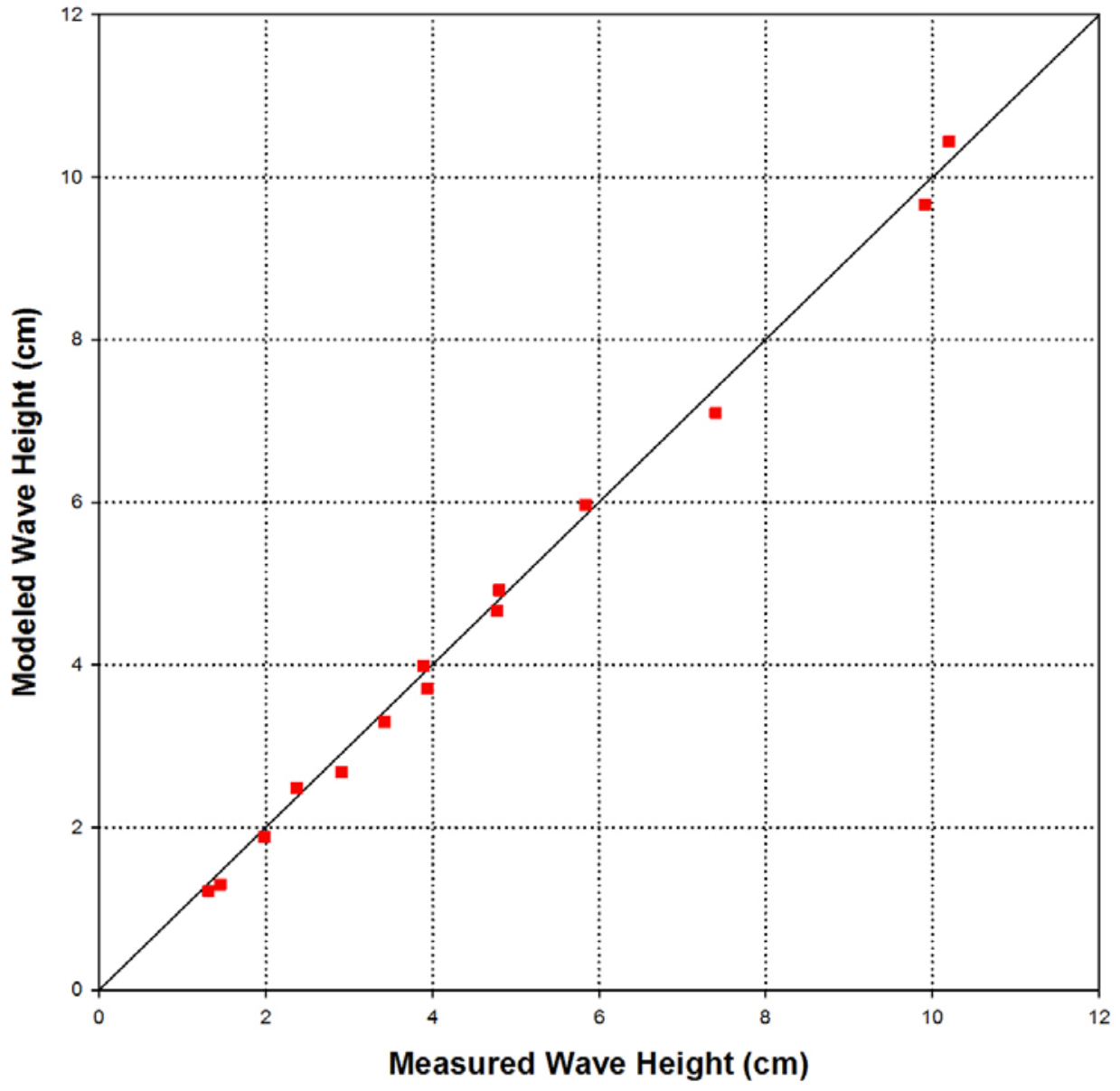

Figure 5. Comparisons between the measured and modeled attenuated wave heights. 
(a)

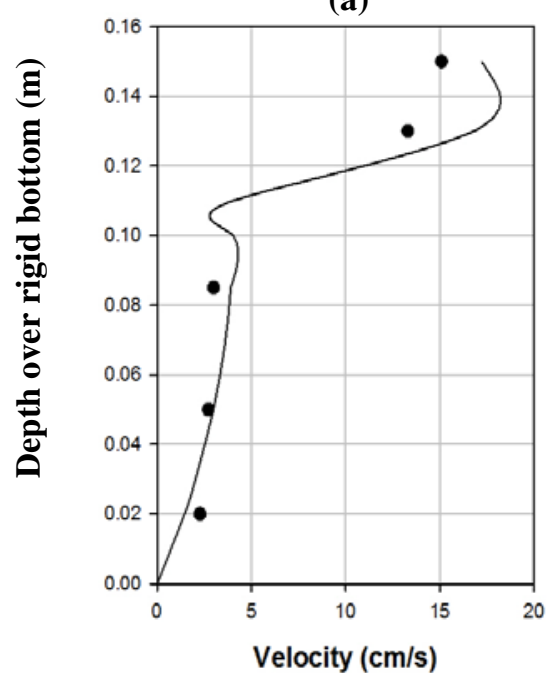

(b)

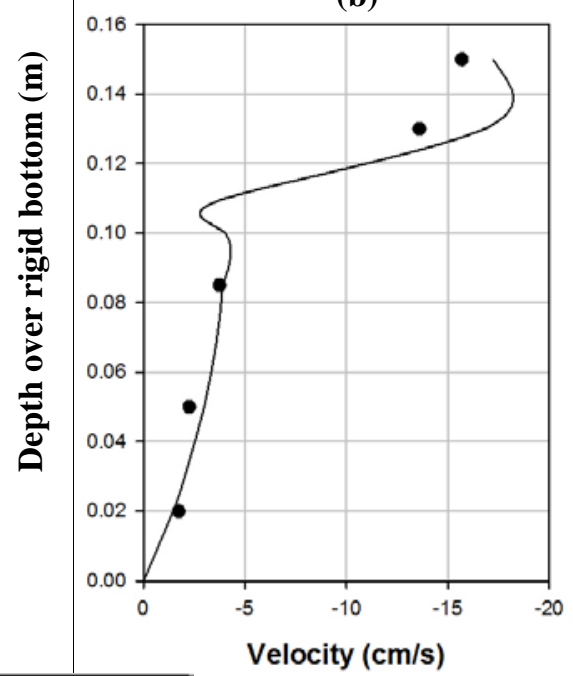

- Measured values Simulations

Figure 6. Comparisons between the experimental and simulated instantaneous velocities $(T=1.1 \mathrm{~s}, H=5.0$ $\mathrm{cm})$, a) under the wave crest; b) under the wave trough.

Fig. 8 provides the measured and modeled phase lags in the depth for a representative case. As expected, the values of phase lags with the free surface in water layer are much lower than the corresponding phase lags in the mud layer. The phase lags in the water layer have been induced by the mud presence and the act of boundary layer effects. Since the ECM devices in the mud and water layers and one wave gauge are positioned in a vertical line, the outputs of the ECMs are automatically synchronized and no synchronization technique is needed here, unlike the study of Hsu et al. (2013). By going up through the depth, the phase lags are decreased. The phase lags values lie among the intervals of 45 to 65 degrees which is comparable to the results provided by Maa and Mehta (1990).

The comparison of simulated and measured mud mass transport have been presented in Fig. 9. It is seen through the figure that the model is rather capable for the prediction of mass transport.

\section{SUMMARY AND CONCLUSION}

The wave-induced mud particle velocities and mass transport were studied through laboratory experiments and numerical modeling. Using ECMs, accurate measurements of particle velocities in the fluid mud layer and better estimations of mud mass transports can be achieved. The results are more reliable in comparison to the traditional method of inserting colored mud. Analyzing the dissipation rates over mud layer showed that the changes of the wave attenuation rates versus wave periods at different wave heights present a common trend of double peaks.

A two-layered model, where the fluid system is divided to fluid mud and water layers, was developed to simulate wave-mud interaction. Different comparisons of the results of the numerical model with laboratory data showed that the model is capable to predict different phenomena of wavemud interaction.

\section{ACKNOWLEDGMENTS}

The study was financially supported by the sabbatical research grant from Iranian ministry of science, research and technology for PhD candidates and also the Strategic Research Foundation Grantaided Project for Private Universities from Japanese Ministry of Education and Waseda University (No. S1311028).

\section{REFERENCES}

An, N.N., and T. Shibayama. 1994. Wave-current interaction with mud bed. Proceedings of $24^{\text {th }}$ International Conference on Coastal Engineering, ASCE, 2913-2927. 

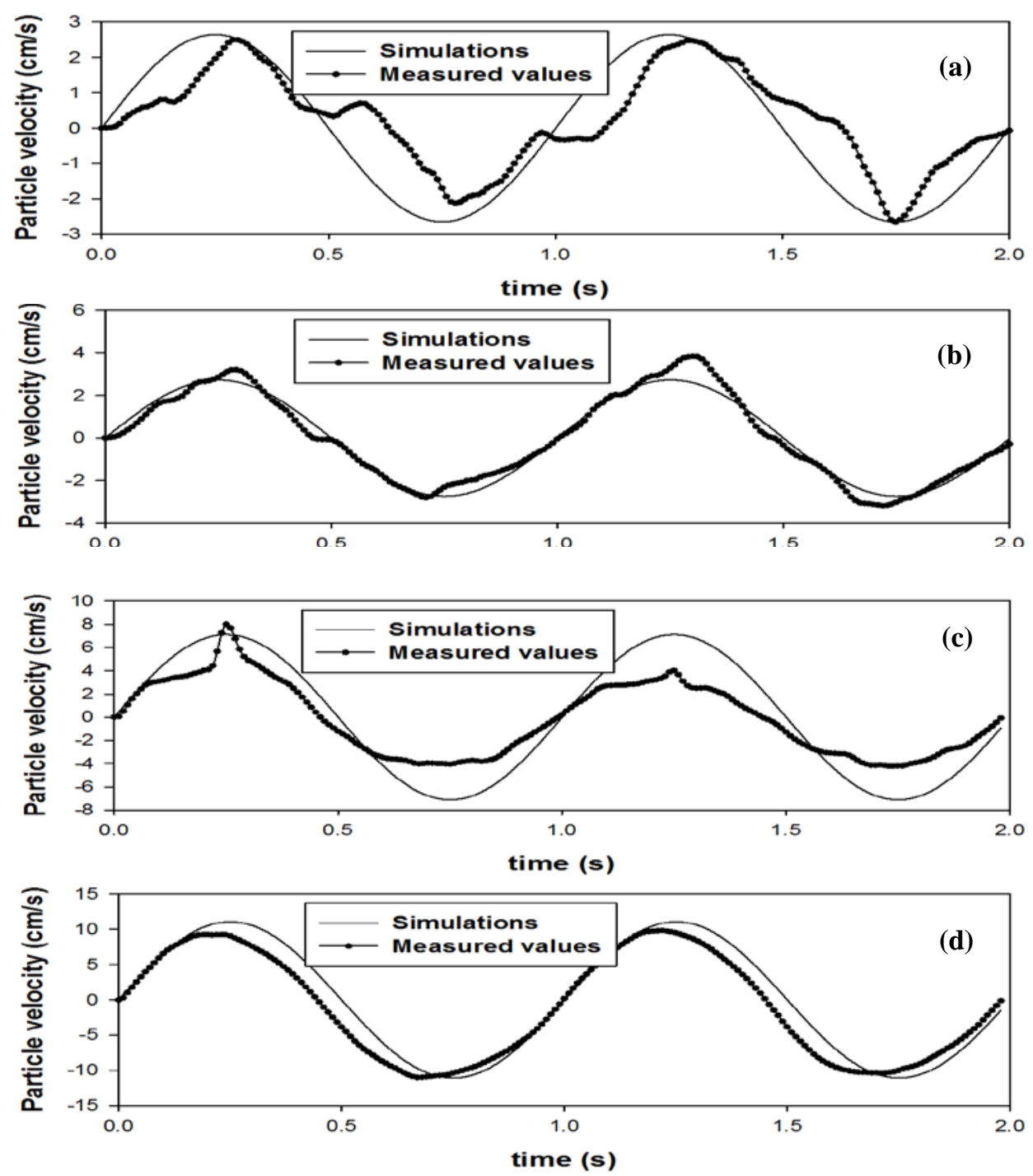

Figure 7. Comparisons between the measured particle velocities and simulations in a representative case of $T=1.0 \mathrm{~s}$ and $H=7.0 \mathrm{~cm}$; a) $z=0.02 \mathrm{~m}$; b) $z=0.05 \mathrm{~m}$; c) $z=0.085 \mathrm{~m}$; d) $z=0.15 \mathrm{~m}$ measured above the rigid bottom.

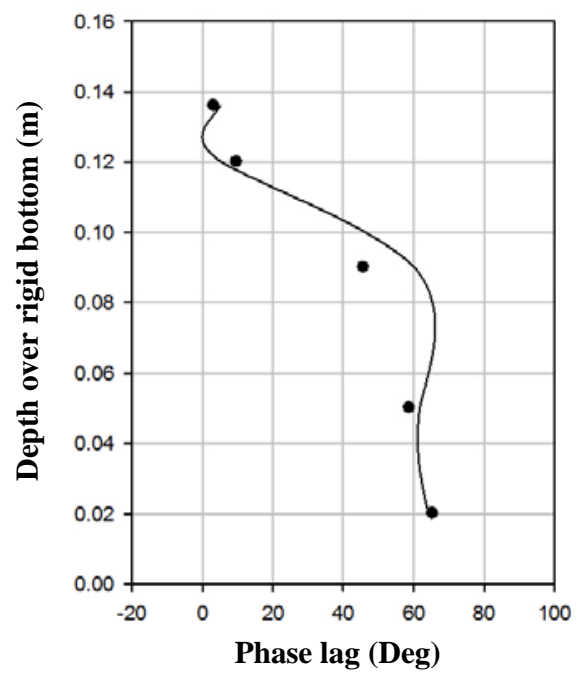

Figure 8. Comparison between the experimental and simulated results of phase lags over the depth $(T=1.1 \mathrm{~s}$, $H=5.0 \mathrm{~cm})$. 

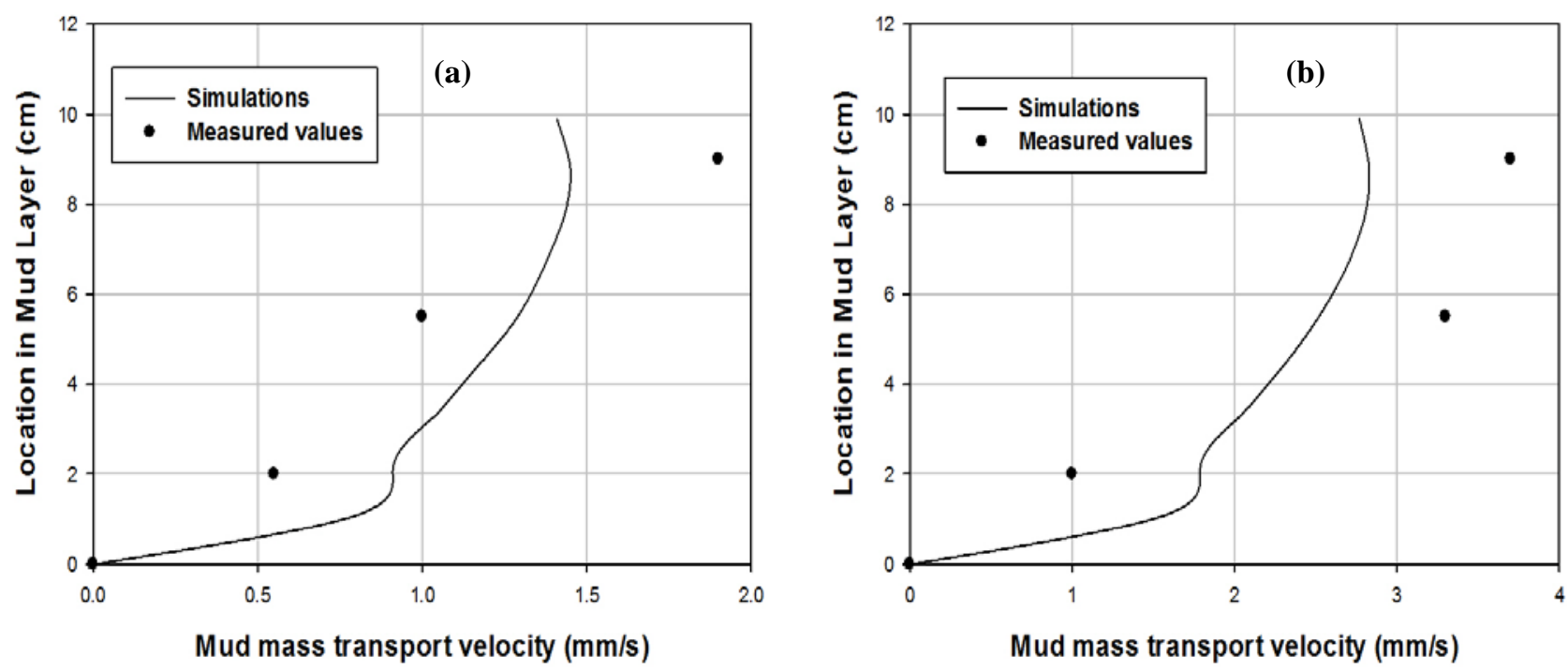

Figure 9. Comparisons between the experimental and simulated results of mud mass transport velocity; a) $T=1.1 \mathrm{~s}, H=5.0 \mathrm{~cm}$; b) $T=1.1 \mathrm{~s}, H=7.0 \mathrm{~cm}$.

Dalrymple, R.A., and P.L. Liu. 1978. Waves over soft muds: a two-layer fluid model. Journal of Physical Oceanography, 8 (6), 1121-1131.

Dore, B.D. 1970. Mass transport in a layered fluid system. Journal of Fluid Machanics, 40, 113-126.

Gade, H.G. 1958. Effects of a nonrigid, impermeable bottom on plane surface waves in shallow water. PhD Thesis, Texas A\&M University, Texas, 35 pp.

Hsu, W.Y., Hwung, H.H., Hsu, T.J., Torres-Freyermuth, A., and Yang, R.Y., An experimental and numerical investigation on wave-mud interactions. Journal of Geophysical Research: Oceans, 118, 1126-1141.

Maa, J.P.Y., and A.J. Mehta. 1990. Soft mud response to water waves. Journal of waterway, port, coastal, and ocean engineering, 116 (5), 634-650.

Sakakiyama, T., and E.W. Bijker. 1989. Mass transport velocity in mud layer owing to progressive waves. Journal of Waterway, Ports, Coastal and Ocean Engineering, ASCE, 115 (5), 614-633.

Shibayama, T., Okuno, M., and S. Sato. 1990. Mud transport rate in mud layer due to wave action. Proceedings of $22^{\text {nd }}$ International Conference on Coastal Engineering, ASCE, 3037-3038.

Soltanpour M., Shibayama T., and Y. Masuya 2007. Irregular wave attenuation and mud mass transport, Coastal Engineering Journal, Vol. 49, No. 2, 127-148.

Soltanpour, M., and F. Samsami. 2011. A comparative study on the rheology and wave dissipation of kaolinite and natural Hendijan Coast mud the Persian Gulf. Ocean Dynamics, 61 (2-3), 295-309. 